\title{
A Rare Soft-Tissue Tumor in a 15-Year-Old Boy With Tuberous Sclerosis Complex: Challenge
}

\author{
Lindsey Oudijk, MD, PhD, ${ }^{*}$ Elodie J. Mendels, MD, $\dagger$ and Jeffrey Damman, MD, PhD*
}

(Am J Dermatopathol 2020;42:e66-e67)

\section{CASE REPORT}

A 15-year-old boy known with tuberous sclerosis complex with a TSC2 mutation and clinical features of hypopigmented macules, facial angiofibromas, mental retardation, epilepsy, angiomyolipoma, and cardial rhabdomyoma presented at our pediatric dermatology clinics. He had a gradually increasing large soft multinodular tumor in the neck (Fig. 1), which had been present for 5 months. At times, the lesion was painful, and the patient noticed purulent discharge. The tumor measured $5.3 \times 3.5 \mathrm{~cm}$ and showed an irregular surface with comedo-like/cystic openings. The patient requested removal of the tumor for cosmetic reasons.

On gross pathology, the specimen showed a diffuse, pale fibrotic appearance, with fibrosis extending into the subcutaneous fat (Fig. 2A). Histopathologic examination of the lesion revealed 3 components: abundant thick collagen bundles in the dermis and underlying adipose tissue; concentric perifollicular, perieccrine, and perivascular fibrosis; and variable-sized epithelial cysts and dilated openings (Figs. 2B-D).

\section{WHAT IS YOUR DIAGNOSIS?}

(Continued on page 460)

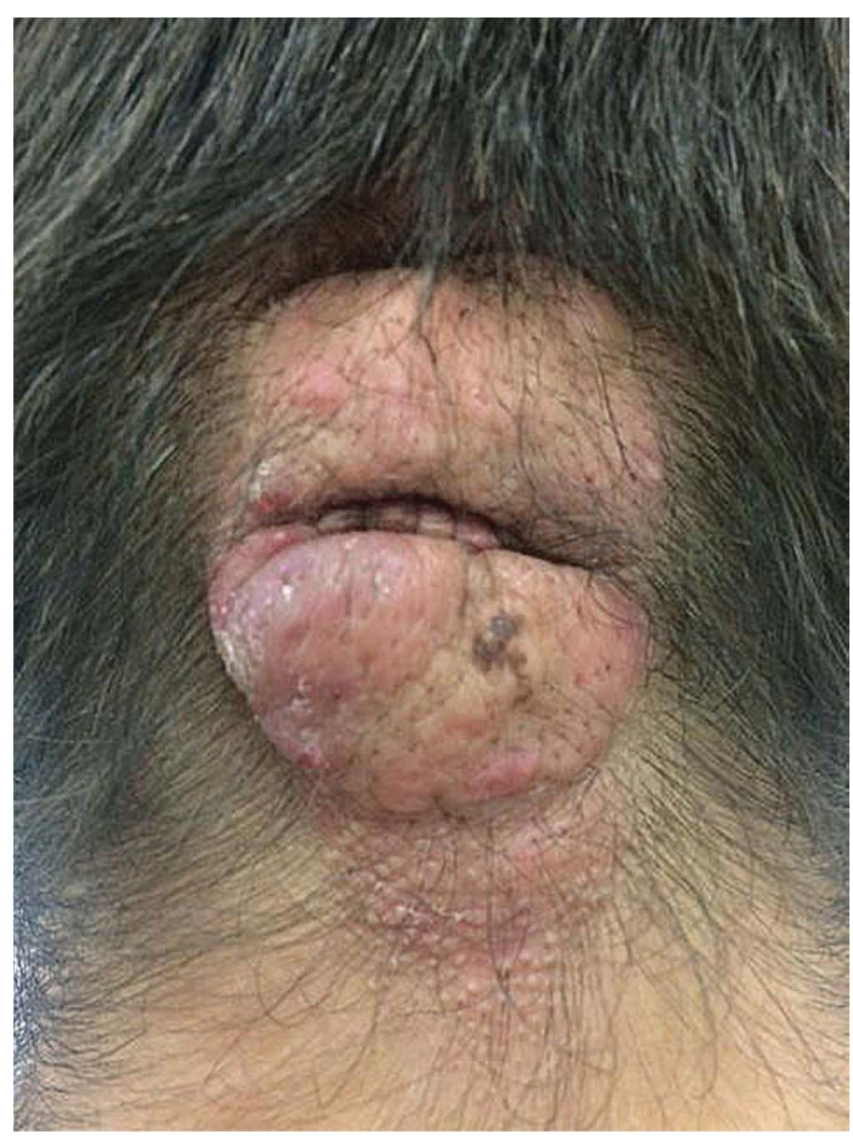

FIGURE 1. Exophytic multinodular tumor in the neck with an irregular surface and comedo-like openings.

From the Departments of *Pathology, and $\uparrow$ Pediatric Dermatology, Erasmus MC, University Medical Center, Rotterdam, the Netherlands.

The authors declare no conflicts of interest.

Correspondence: L. Oudijk, Department of Pathology, Erasmus University Medical Center Rotterdam, Doctor Molewaterplein 40, 3015 GD Rotterdam, the Netherlands (e-mail: 1.oudijk@erasmusmc.nl).

Copyright (C) 2019 Wolters Kluwer Health, Inc. All rights reserved. 

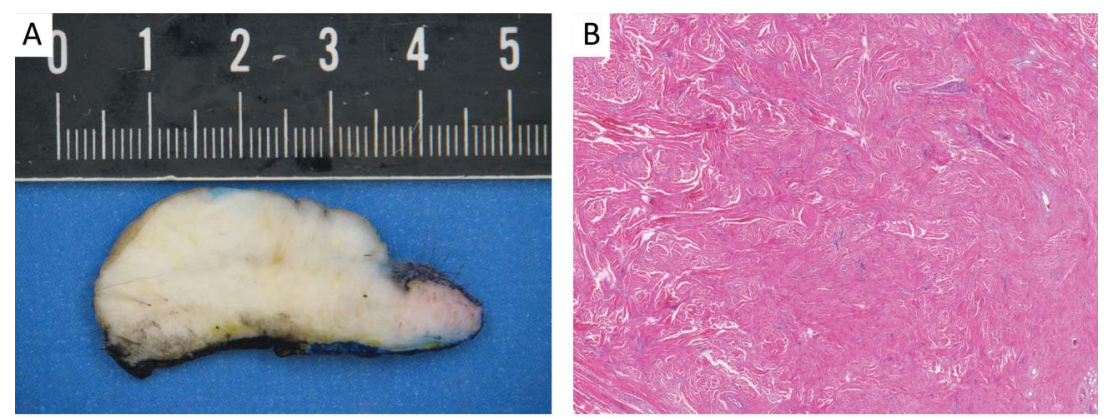

FIGURE 2. Gross pathology shows a diffuse, pale fibrotic rubbery appearance (A). Histopathology reveals abundant thick haphazardly arranged collagen bundles in the dermis and subcutis (B), concentric variable-sized epithelial cysts/dilatation of hair follicles (C), and profound perifollicular fibrosis (D, arrow).
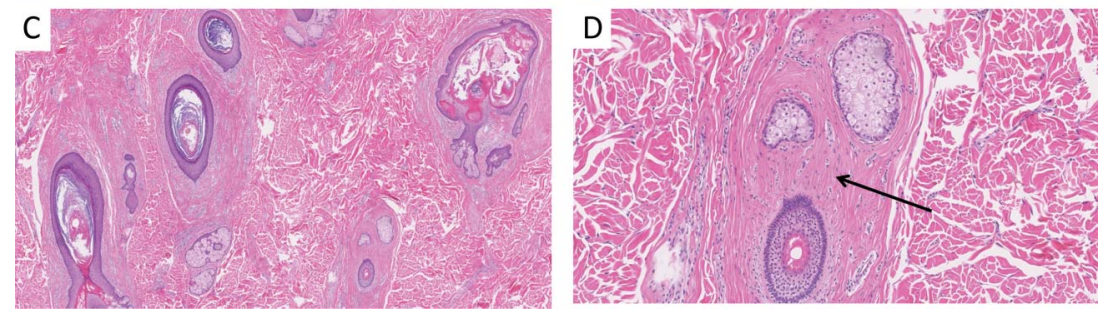